\title{
Implementasi Konsep Pentahelix Dalam Pengembangan Desa Wisata Cibuntu
}

\author{
Pusparani ${ }^{(1)}$, Rianto $^{(2)}$ \\ Sekolah Tinggi Pariwisat Trisakti Jakarta \\ pusparani@stptrisakti.ac.id
}

\begin{abstract}
Abstrak
Pembahasan penelitian di titikberatkan pada pnerapan konsep Penta Helix dalam pengembangan desa wisata di Cibuntu. Penelitian ini merupakan studi kasus, narasumber dalam penelitian ini sebanyak lima orang yangmerupakan perwakilan dari pebisnis, pemerintah, komunitas, akademisi dan media. Hasil penelitian menunjukkan bahwa pelaksanaan konsep Pentahelix telah berjalan dengan baik. Koordinasi dan kolaborasi yang sinergis dari masing-masing elemen Pentahelix mengantarkan Desa Wisata Cibuntu meraih beberapa penghargaan dalam bidang pariwisata.Koordinasi dan kolaborasi yang telah terbangun antara pihak pemerintah, pelaku bisnis pariwisata, komunitas, akademisi,serta media perlu dipertahankan.

Kata kunci : desa wisata, pentahelix

Abstract

The research discussion focuses on the application of the Penta Helix concept in the development of a tourist village in Cibuntu. This research is a case study. The sources of this research are five people who are representatives of business people, government, community, academia and the media. The results show that the implementation of the Pentahelix concept has gone well. The synergic coordination and collaboration of each Pentahelix element has led Cibuntu Tourism Village to win several awards in the tourism sector. The coordination and collaboration that has been built between the government, tourism business actors, communities, academics, and the media need to be maintained
\end{abstract}

Key word : Tourism village, Pentahelix 


\section{PENDAHULUAN}

Sejalan dengan pelaksanaan otonomi daerah, Kabupaten Kuningan telah mengembangkan desa wisata dibeberapa desa yang mempunyai potensi sebagai destinasi wisata yang salah satunya adalah desa Cibuntu. Desa Wisata Cibuntu yang terletak di Kecamatan Pesawahan, telah berdiri menjadi desa wisata sejak tahun 2012. Dalam perkembangannya desa Cibuntu ini telah meraih banyak prestasi dan penghargaan. Desa Cibuntu pernah dinobatkan menjadi desa wisata terbaik urutan lima tingkat ASEAN pada tahun 2016 untuk bidang homestay. Pada tahun 2017, Cibuntu terpilih sebagai desa wisata terbaik peringkat dua di Indonesia dalam ajang Community Based Tourism (CBT) yang diselenggarakan oleh Kementerian Pariwisata Indonesia. Lalu pada tahun 2019, Cibuntu meraih penghargaan tingkat nasional berupa Indonesia Sustainable Tourism Award (ISTA). Jika dilihat dari jumlah kunjungan wisatawan yang berkunjung ke desa Cibuntu, data menunjukkan bahwa setiap tahunnya sampai tahun 2018 ada kenaikan jumlah pengunjung.

Tabel 1.

Jumlah Kunjungan Wisatawan ke Desa Cibuntu (2012 - 2019)

\begin{tabular}{|c|c|c|c|}
\hline No & Tahun & Jumlah Kunjungan & $\%$ Kenaikan \\
\hline 1 & 2012 & 2.457 & \\
\hline 2 & 2013 & 3.385 & $38 \%$ \\
\hline 3 & 2014 & 5.772 & $71 \%$ \\
\hline 4 & 2015 & 11.276 & $95 \%$ \\
\hdashline 5 & 2016 & 11.381 & $1 \%$ \\
\hdashline 6 & 2017 & 19.385 & $70 \%$ \\
\hdashline 7 & 2018 & 65.014 & $235 \%$ \\
\hdashline 8 & 2019 & 42.894 & $-34 \%$ \\
\hline
\end{tabular}

Keberhasilan pembangunan sektor wisata tidak terlepas dari kolaborasi secara sinergis dari berbagai pihak. Industri pariwisata sebagai salah satu penggerak pertumbuhan ekonomi, sering kali hasilnya kurang optimal dalam menggerakkan sektor perekonomian yang salah satu sebabnya adalah kurangnya koordinasi di antara berbagai elemen-elemen terkait. Sinkronisasi dari berbagai sektor pariwisata merupakan modal dasar bagi tercapainya pembangunan pariwisata. Peraturan Menteri (Permen) Pariwisata Republik Indonesia Nomor 14 Tahun 2016 Tentang Pedoman Destinasi Pariwisata Berkelanjutan menyatakan bahwa agar pariwisata memberikan keuntungan dan manfaat pada masyarakat dan lingkungannya maka perlu adanya interkoneksitas sistem, subsistem, sektor, dan juga dimensi sehingga tercipta orkestrasi yang terintegrasi secara optimal baik peran bussiness, government, community, academic, dan media (BGCAM) yang dikenal dengan Konsep Penta Helix.

Menurut Rampersad, Quester, \& Troshani, dalam Halibas, Sibyan, dan Maat (2017) bahwa kolaborasi pentahelix mempunyai peran penting di dalam mendukung tujuan inovasi bersama dan pentahelix juga berkontribusi terhadap kemajuan sosial ekonomi daerah.

Desa Cibuntu sebagai salah satu destinasi wisata diharapkan dalam pelaksanaan pembangunan pariwisatanya juga telah menerapkan kolaborasi dari berbagai sektor secara sinergi dengan melibatkan peran dari pebisnis, pemerintah, masyarakat, akademisi dan juga media. Untuk melihat sejauh mana Implementasi Konsep Kolaborasi Pentahelix pada Desa Wisata Cibuntu maka penelitian ini dilakukan. 


\section{METODOLOGI}

Penelitian ini dilakukan dalam rangka untuk melihat bagaimana implementasi kolaborasi model Penta Helix dalam pengembangan desa wisata Cibuntu. Metode yang digunakan dalam penelitian ini adalah melalui pendekatan kualitatif dengan menggunakan penelitian studi kasus (case study), narasumber atau informan yang diwawancarai dalam penelitian ini sebanyak 5 orang merupakan perwakilan dari masing masing unsur Penta Helix yaitu pebisnis, pemerintah, komunitas, akademisi dan media.

Untuk melengkapi data yang diperoleh dari hasil wawancara dengan informan, dilakukan juga kajian literatur baik berupa jurnal maupun buku-buku penunjang, surat kabar, majalah, laporan publikasi riset dengan studi empiris dari lembaga kompeten. Analisis yang digunakan dalam penelitian dilakukan dengan cara yang logis, sistematis, serta argumentatif yang kritis.

\section{HASIL DAN PEMBAHASAN}

\section{a. Peran Akademisi}

Berdasarkan hasil wawancara dengan bapak Agie Pradipta selaku informan yang mewakili akademisi, diungkapkan bahwa pada tahun 2011, tim pascasarjana Trisakti mengadakan penelitian yang terdiri atas dosen dan mahasiswa pascasarjana. Tim pascasarjana menemukan hasil identifikasi bahwa Cibuntu memiliki potensi luar biasa untuk dijadikan destinasi pariwisata dan Desa Wisata.

Menurut informan, bahwa potensi destinasi wisata yang dimiliki oleh desa apabila dikelola dan dikemas dengan baik akan menjadi atraksi yang menarik bagi wisatawan dan dapat membuka lapangan kerja bagi masyarakat setempat.
Terkait dengan kolaborasi model Pentahelix, menurut bapak Agie Pradipta berpendapat bahwa peran akademisi terbagi dalam beberapa tahapan yaitu :

1) Tahap awal persiapan pembentukan desa wisata dengan cara melakukan identifikasi potensi destinasi wisata desa yang dilakukan pada tahun 2011

2) Tahap pelaksanaan pembentukan desa wisata, pihak akademisi memberikan pelatihan dalam bidang kepariwisataan diantaranya meliputi : character building, guiding, dan juga pengembangan digital product. Pelatihan tersebut mencakup bagaimana pemenuhan fasilitas suatu penginapan (homestay), pemberian layanan yang baik kepada pengunjung yang datang dan bermalam dirumah penginapan, serta pelatihan dalam diversifikasi kuliner dengan memanfaatkan bahan yang ada di desa.

3) Tahap Pemantauan dengan melakukan evaluasi dan saran terhadap perbaikan apa yang telah dicapai dan apa yang perlu diperbaiki dalam mencapai tujuan

b. Peran Pemerintah

Berdasarkan hasil wawancara dengan bapak Ritto Riswanto selaku informan yang mewakili pemerintah, diungkapkan bahwa sebagai regulator peran pemerintah dalam pembentukan desa wisata ini mencakup dari awal persiapan pembentukan desa wisata sampai dengan tahapan monitoring dan evaluasi.

1) Tahap awal (persiapan) peran pemerintah adalah berawal dengan menyamakan pandangan masyarakat, pemerintah desa, lembaga tingkat desa tentang bagaimana membuat satu komitmen bagaimana bersama sama mewujudkan desa wisata, pendekatan-pendekatan secara persuasif dan kontinyu, melakukan pertemuan formal dan non-formal melibatkan komponen masyarakat, anak muda, ibu- 
ibu, kelompok petani, kelompok UMKM, karang taruna, dan lembaga masyarakat desa lain. Membentuk lembaga, memberikan penguatan kepada organisasi tingkat desa, dan menyusun perencanaan visi untuk penataan Desa Cibuntu. Lalu ada deklarasi dan ada kajian akademis, pembuatan PERDA dan Peraturan Desa

2) Tahap Pelaksanaan Pembentukan Desa Wisata peran pemerintah adalah sebagai berikut :
a)
Perencanaan dan

penyediaan anggaran dalam pengadaan dan perbaikan infrastruktur penunjang bagi destinasi desa wisata Cibuntu

b) Memberikan Pelatihan dan Bimbingan Teknis kepada masyarakat untuk penyelenggaraan event, workshop, pelatihan-pelatihan, sertifikasi guide (pemandu wisata), guna mengembangkan sumber daya yang ada agar masyarakat lebih sadar wisata, lebih kreatif dan memiliki rasa tanggung jawab sebagai tuan rumah pengelola homestay, pengemasan kuliner, pelayanan pariwisata

c) Perumus kebijakan dan perijinan

3) Tahap Monitoring dan Evaluasi

Melakukan monitoring atas pembentukan desa wisata dan melakukan evaluasi bagi perbaikan pengelolaan desa wisata

c. Peran Masyarakat

Berdasarkan hasil wawancara dengan bapak Adang selaku informan yang mewakili masyarakat, diungkapkan bahwa Masyarakat Cibuntu berperan sebagai pelaku utama dalam proses pengembangan desa wisata Cibuntu yang dimulai dari tahap persiapan, pelaksanaan dan monitoring dan evaluasi.

\section{1) Tahap Persiapan}

Mengikuti pertemuan baik formal maupun nonformal dengan semua pemangku kepentingan dalam rangka pembentukan desa wisata, membentuk kelompok, mengikuti pelatihan yang diselenggarakan oleh akademisi, pemerintah maupun pihak lainnya mulai dari pelatihan dan pembelajaran informasi, cara pelayanan untuk tamu, pengetahuan tentang kearifan lokal dan lingkungan, menjaga kebersihan pada homestay, dan pelatihan ekonomi kreatif di desa,

\section{2) Tahap Pelaksanaan}

Melakukan pembenahan dan penataan infrastruktur pendukung daerah wisata yang belum tersentuh, membuat kerajinan tangan untuk cendramata, oleh-oleh, dan kuliner dari hasil tani seperti jasreh dan pukis rebung. Menjadi guide (pemandu wisata), karena masyarakat yang paling mengenal daerah sendiri

3) Tahap Monitoring dan Evaluasi

Melakukan monitoring dan evaluasi sebagai upaya perbaikan pengembangan desa wisata atas saran dan masukan semua pihak terkait termasuk dari wisatawan yang pernah berkunjung ke desa tersebut .

d. Peran Pebisnis

Berdasarkan hasil wawancara dengan bapak Fajar informan yang mewakili pebisnis, diungkapkan bahwa peran pebisnis sebagai industri biro perjalanan wisata adalah :

1) Tahap pelaksanaan dengan melakukan pengembangan produk tour dengan membuat dan menjual paket paket desa wisata Cibuntu melalui analisis potensi desa seperti situs bersejarah, masyarakat yang ramah, keindahan alam, dan pertanian untuk dirangkai menjadi produk wisata. Menurut infoman peran industri sangat penting, karena travel agent berperan penting dalam mendatangkan tamu untuk mewujudkan desa wisata, mengenalkan, mempresentasikan keseluruhan paket wisata yang ada. Sebenarnya peluang bisnis sangat besar 
karena desa Cibuntu memiliki potensi alam, kesenian, dan kebudayaan yang menarik sehingga menjadikan industri lebih mudah untuk menjual Desa Cibuntu untuk menjadi Desa Wisata, dan mendatangkan tamu dan menguntungkan kedua belah pihak

2) Tahap Monitoring dan Evaluasi, peran pebisnis adalah memberikan masukan atas hal hal yang masih kurang bagi perbaikan Desa Wisata, sesuai dengan masukan dari wisatawan yang telah berkunjung di desa tersebut.

e. Peran Media

Berdasarkan hasil wawancara dengan bapak Bambang Priatna selaku infoman yang mewakili industri media bahwa peran media adalah :

1). Mendukung publikasi dalam promosi dan membuat brand image Cibuntu. Dalam program pengembangan Desa Cibuntu melalui website http://desacibuntu.com/ sebagai media untuk promosi dan informasi.

Dalam digital ini kebutuhan promosi adalah hal utama. Suatu destinasi wisata sebaiknya sudah mempunyai website dan media sosial, karena setiap kali wisatawan ingin berkunjung ke tempat wisata hal pertama kali yang dilakukan adalah searching di media digital untuk mencari informasi terkait tempat wisata tersebut. tentang tempat tersebut. Sebagai tempat publikasi dan promosi agar bisa dikenal oleh orang banyak, peliputan kegiatan yang ada pada desa wisata termasuk kehidupan masyarakat dan adat istiadatnya serta penghargaan yang telah dicapai, liputan berita yang disajikan harus sesuai dengan kenyataan yang ada dilapangan sehingga wisatawan akan mendapatkan informasi yang benar. Sebaiknya liputan tersebut tidak terlalu melambungkan dan mem-booming kan suatu destinasi wisata karena promosi yang paling baik adalah dari testimoni dan tulisan dari orang lain yang pernah berkunjung ke destinasi wisata tersebut . Menurut Pak Bambang indah dan lain sebagainya itu relatif, yang pasti Desa Wisata Cibuntu harus dapat memberikan kenangan baik untuk diingat dan memiliki rasa ingin kembali

2). Selain itu media juga menyebarluaskan informasi tentang Desa Wisata Cibuntu melalui media daring sebagai penghubung antara masyarakat, pengusaha dengan pemerintah. Dan media juga berperan penting dalam membantu perkembangan pariwisata di Desa Cibuntu.

Sejak awal ditetapkansebagai desa wisata, kunjungan wisatawan ke desa Cibuntu setiap tahunnya mengalami peningkatan jumlah wisatawan. Hal ini tidak terlepas dari terbangunnya kolaborasi yang melibatkan berbagai elemen yang ikut berperan dalam pelaksanaan konsep Pentahelix yakni akademisi, pemerintah, masyarakat, pebisnis dan media dalam mendukung terbentuknya desa wisata

Dari hasil wawancara yang telah dilakukan dengan ke-lima narasumber, bisa dikatakan bahwa semua pilar atau bidang dari Penta Helix telah terlaksana dan terwujud di Desa Wisata Cibuntu. Peran masing-masing pilar sesuai dengan kapabilitas dan perkembangan dari waktu ke waktu diikuti dengan kolaborasi yang sinergis dari seluruh unsur Penta Helix pariwisata yang terlibat dalam usaha mengembangkan desa wisata Cibuntu memberikan dampak pemberian beberapa penghargaan besar atas prestasi yang diraih oleh Desa Cibuntu. Hal ini terjadi karena kekuatan semua komponen pelaku wisata yang ada dalam konsep Penta Helix, telah melakukan peranan masing masing. 
Peranan masyarakat sangat penting karena yang menjadi pelaku pariwisata desa wisata adalah masyarakat itu sendiri. Konsep pemberdayaan masyarakat, sebisa mungkin masyarakat harus terjun langsung untuk menjadi pelaku pariwisata.Hubungan yang baik antara masyarakat dan akademisi/perguruan tinggi menjadi modal dasar dalam mewujudkan Cibuntu sebagai Desa Wisata. Hal ini tentu memberikan dampak positif bagi masyarakat karena adanya penambahan wawasan yang diperoleh dari akademisi.

Akademisi telah memberikan bantuan berbasis pengetahuan dan bentuk pengembangan kapasitas bagi komunitas Desa Cibuntu sehingga membangkitkan kesadaran komunitas Desa Cibuntu akan potensi wisata yang dimiliki dan kebutuhan untuk melakukan pembenahan terhadap masalah yang ada.Akademisi juga telah membimbing masyarakat menjadi sadar wisata dan dapat menerapkan konsep Sapta Pesona. Bantuan dan kerjasama antar pelaku pariwisata akan membantu terwujudnya capaian pengembangan desa wisata yang pada akhirnya akan mampu mensejahterakan masyarakat desa sebagai imbas dari banyaknya kunjungan wisatawan yang mengunjungi dari desa wisata tersebut.

Pemerintah sebagai pendorong memberikan motivasi kepada masyarakat agar lebih meningkatkan kinerja sebagai pelaku pariwisata di desa. Peran pemerintah juga untuk membuka lapangan pekerjaan, memberikan pedampingan, monitoring, evaluasi, pengawasan, pembinaan, memberikan perizinan.
Peranan Pebisnis juga tidak kalah penting, yaitu membantu penyediaan infrastrukur penunjang seperti membuat camping ground(bumi perkemahan), kolam renang, dan juga kegiatan konservasi bersamasama dengan masyarakat agar pembangunan desa wisata berkelanjutan.Peran pebisnis yang tidak kalah penting lainnya adalah dalam membuat dan menjual paket- paket wisata.

Salah satu aspek dalam pariwisata adalah media, yang berfungsi sebagai penghubung antara masyarakat, pengusaha dengan pemerintah. Dan media juga berperan penting dalam membantu perkembangan pariwisata. Peran media sendiri harus bisa memberikan stigma positif tentang desa wisata tersebut.

\section{KESIMPULAN}

Berdasarkan hasil yang telah diperoleh dari pembahasan pada bab sebelumnya mengenai Implementasi Konsep Penta Helix di Desa Wisata Cibuntu, maka dapat ditarik kesimpulan sebagai berikut:

Pelaksanaan konsep Penta Helix di Desa Wisata Cibuntu telah berjalan dengan baik. Koordinasi dan kolaborasi yang sinergis dari setiap pilar pada akhirnya mampu membuahkan hasil Desa Wisata meraih berbagai penghargaan sebagai sebuah Desa Wisata.

Peran masing masing pilar Penta Helix dapat disarikan dalam tabel berikut : 
Sadar Wisata: Jurnal Pariwisata

Volume 4 No. 1 Juni Tahun 2021

(p- ISSN 1858-0112, e-ISSN 15537-37677) http://jurnal.unmuhjember.ac.id/index.php/wisata

\begin{tabular}{|c|c|c|}
\hline Tahapan Perkembangan Desa Wisata & Pelaku & Peran \\
\hline \multirow{7}{*}{ Persiapan Pembentukan Desa Wisata } & \multirow{3}{*}{ Pemerintah } & Melakukan Kajjan Akademis \\
\hline & & Desiminasi Visi Pembentukan Desa Wisata \\
\hline & & Penataan Organisasi \\
\hline & Akademisi & Identifikasi Potensi Desa Wisata \\
\hline & \multirow{3}{*}{ Masyarakat } & Mengikuti Pertemuan Formal maupun Non Formal dengan Pemerintah dan Akademisi \\
\hline & & Pembentukan Lembaga \\
\hline & & Mengikuti Pelatihan yang diberikan oleh Pemerintah dan Akademisi \\
\hline \multirow{13}{*}{ Pelaksanaan Desa Wisata } & \multirow{5}{*}{ Pemerintah } & Perencanaan dan Anggaran \\
\hline & & Pendampingan \\
\hline & & Pelatihan \\
\hline & & Perijinan \\
\hline & & Perumus Kebjiakan \\
\hline & Akademisi & Pelatihan \\
\hline & \multirow{3}{*}{ Masyarakat } & Pembenahan dan Penataan Infrastruktur Pendukung Pariwisata \\
\hline & & Penvediaan Fasilitas Pendukung Desa Wisata (homestay, cinderamata) \\
\hline & & Mengikuti Pelatihan yang diberikan oleh Pemerintah dan Akademisi \\
\hline & \multirow{3}{*}{ Pebisnis } & Pengemasan paket produk wisata \\
\hline & & Penvediaan sarana dan prasarana destinasi wisata \\
\hline & & Promosi produk wisata \\
\hline & Media & Promosi dan Publikasi \\
\hline \multirow{6}{*}{ Monitoring dan Evaluasi } & \multirow{2}{*}{ Pemerintah } & Pengawasan \\
\hline & & Evaluasi \\
\hline & Akademisi & Masukan untuk upava perbaikan \\
\hline & Masyarakat & Pelaksana perbaikan atas masukan dan evaluasi dari semua stakeholder \\
\hline & Pebisnis & Evaluasi pembuatan paket perjalanan wisata atas masukan wisatawan \\
\hline & Media & Masukan untuk upaya perbaikan \\
\hline
\end{tabular}




\section{DAFTAR PUSTAKA}

Halibas Alrence Santiago, Sibayan, Rowena Ocien, Maata, Rolou Lyu Rodrigues (2017) The Pentahelix Model Of Innovation

Kotler, P., Bowen, J \& Makens, J (2006) Marketing for hospitality \& Tourism $\left(4^{\text {th }}\right.$ ed $)$ Upper Saddle River, NJ:Prentice hall

Pitana (2009) Pengantar Ilmu Pariwisata, Yogyakarta : Penerbit Andi

Satari, F.C \& Asad, N (2016). Model strategi Pengembangan Wirausaha \& Ekonomi kreatif di Tingkat kota (Pemetaan Perkecamatan) di Bandung, dengan pendekatan Ekosistem Ekonomi kreatif, SWOT, identifikasi peran (Pentahelix) Stakeholders \& Rencana Aksi Implementasinya, Bandung, Retrieved from http://www.feb.unpad,ac,id/dokumen/fi les/01-Laporan-

Kemajuan_RFU_FINAL pdf

Soemaryani Imas (2016). Pentahelix Model To Increax Tourist Visit To Bandung \& Its Surrounding Areas Through Huan Rescue Development. Academy of Strategic Management Journal Vol 15, Special Issues, 2016

Wang, Youcheng \& Pizam, Abraham (2011). Destinations Marketing \& Management. Theories \& Applications, Oxford: CABI Publishing. 